\title{
In vitro Cytotoxic, Antioxidant and Antimicrobial Activities of Alcoholic and Chloroform Extracts of Dhofari Frankincense
}

\author{
Alaa M. Soliman ${ }^{1}$, Raniah R. Majeed ${ }^{1}$, Hala F. Al Himyari ${ }^{1}$, \\ Dhanalekshmi UM ${ }^{2}$ and Shah A. Khan ${ }^{1,2}$ \\ ${ }^{1}$ Department of Pharmacy, Oman Medical College, Muscat, Sultanate of Oman \\ ${ }^{2}$ College of Pharmacy, National University of Science and Technology, Muscat, \\ Sultanate of Oman
}

(Received: February 5, 2020; Accepted: July 1; Published (web): December 10, 2020)

\begin{abstract}
Omani (Dhofari) frankincense is world famous for its high quality and fragrance. The oleo-gum resin obtained from the tree of Omani species i.e., Boswellia sacra (local name: luban) is widely used by the natives. The aim of the study was to determine the presence of phytochemicals in chloroform and ethanol extracts of $B$. sacra resin and to evaluate the in vitro cytotoxic, antimicrobial- and antioxidant-activities. The ethanol and chloroform extracts of Hojari luban were obtained in good yield. The extracts were subjected to phytochemical screenings, quantification of total phenolics (TP) and evaluation of in vitro biological activities viz. antioxidant, antibacterial and cytotoxic potential. The bioactivities of four boswellic acids, the major constituents of the oleo-gum resin, were also predicted with the help of PASS and CLC-pred software. Both the extracts showed similar level of TP (14.67 mg/g and $14.79 \mathrm{mg} / \mathrm{g}$ in terms of gallic acid equivalent) but polar fraction was noted to be more active against $E$. coli. A moderate antioxidant activity was shown by the resin extracts however their cytotoxic activity was observed to be quite remarkable at $1000 \mu \mathrm{g} / \mathrm{l}$ which could be attributed to their high boswellic acid content. Results of in silico PASS studies showed boswellic acids to possess an array of useful biological activities including chemopreventive activity. Further, CLC-pred software revealed that only keto boswellic acid is expected to exert antineoplastic activity against pancreatic carcinoma cell lines, however all the four major boswellic acids are likely to be active against non-tumor embryonic lung fibroblast (MRC5). The study confirmed that frankincense is rich in bioactive metabolites which are of significant economic and therapeutic importance.
\end{abstract}

Key words: Boswellia sacra; Cytotoxic activity; DPPH; Frankincense; In silico studies

\section{INTRODUCTION}

Boswellia sacra (B. sacra) is the scientific name of the oleo gum resin obtained from the tree of Omani frankincense (in Arabic: luban) which belongs to the family Burseraceae. This species of Arabian Peninsula has been regarded as the source of one of the highest quality and the best aromatic gum-resins. ${ }^{1}$ It's obtained by making an incision in the tree bark. The secreted resin upon drying is hardened and is called "tears". There are different types of frankincense which are graded according to various parameters such as age, shape, color, purity and aroma. Among all the types of frankincense, native people consider Hojari variety to be of superior quality because of its white color, aroma and purity. ${ }^{2}$

Correspondence to: Shah Alam Khan

Tel: 00968-24235012;

E-mail: shahalam@nu.edu.om, sakhan@omc.edu.om

Dhaka Univ. J. Pharm. Sci. 19(2): 105-110, 2020 (December) DOI: https://doi.org/10.3329/dujps.v19i2.50624
Oman is known for the trade of Dhofari frankincense to the other parts of the world since ancient time. The oleo gum resin is one of the most common house hold items in Oman. It is used in day to day life either for therapeutic or spiritual purposes forming a part of the traditional Omani life and therefore is considered as a sign of Omani culture. $^{3}$ These trees contain resin as a mechanism of defense against its injury, to protect against insects, fungal attack and decay. Frankincense is widely used in perfumes, aromatherapy, anti-aging and anti-wrinkle preparations. In addition, it can be used in cold and flu, inflammation, pain and to relive the symptoms of indigestion. ${ }^{4}$

The main biologically active phytochemicals of frankincense have been identified as a group of pentacyclic triterpenes known as boswellic acids (Figure 1). Several biochemical studies indicated the role played by these boswellic acids in the 
inhibition of pro-inflammatory enzymes. The most important boswellic acid is acetyl keto boswellic acid (AKBA), which has shown its effectiveness against a considerable number of inflammatory diseases and cancer. AKBA is a selective, noncompetitive and non-redox inhibitor of 5lipoxygenase (5-LO) enzyme. It inhibits this inflammatory enzyme reversibly and in a calciumdependent manner. ${ }^{5}$

Recently, the overspread of detrimental microorganisms and their drug resistance has become challenging to the pharmaceutical world. Most of the antibiotics available in the market to treat severe infections are becoming ineffective due to the development of resistance. In the drug discovery and development process, natural plants and their bioactive compounds are used as source of lead molecules, an alternative to antibiotics. ${ }^{6}$ To overcome the challenge of antimicrobial drug resistance, new compounds with the ability to potentiate the existing drug regime, are very much sought after. Considering the vast potentiality of medicinal plants as sources for antioxidant, antimicrobial and cytotoxic drugs, the present study was designed to explore the in vitro antioxidant, antibacterial and cytotoxic activities of the chloroform and ethanol extracts of Oman's Hojari variety of oleo gum resin including the presence of phytochemicals. In silico studies using PASS and CLC-pred software were also carried out to support the results of experimental studies.

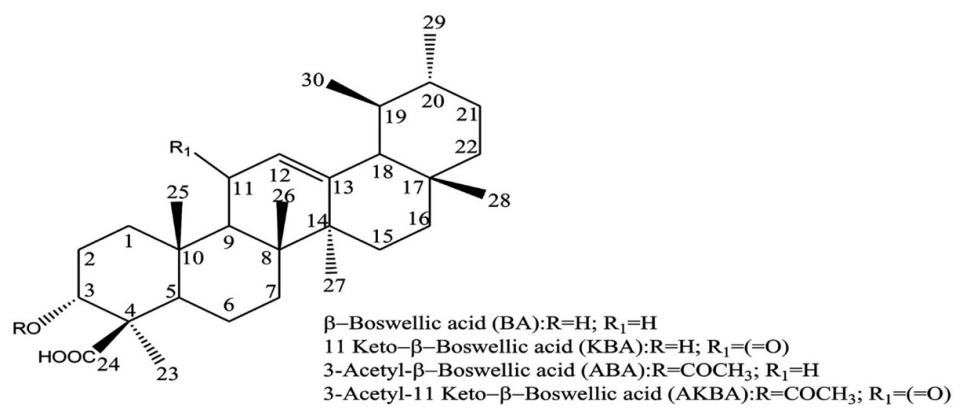

Figure 1. Chemical structure of four naturally occurring $\beta$-boswellic acids.

MATERIALS AND METHODS

Collection of the resin. The frankincense (luban) was purchased from Muscat in the month of August, 2017 and was authenticated by a phytochemist (BP/PHAR425/2017-A3). The samples were coarsely powdered using domestic blender and stored in air tight glass containers until use.

Chemicals and solvents. Analytical grade chemicals and solvents were used in the study and were procured through a local supplier and were used without further purification.

Preparation of $B$. sacra oleo gum resin extracts. The extracts were prepared by cold maceration method. The powdered resins (184.7 $\mathrm{g}$ and $165.5 \mathrm{~g}$ respectively) were exhaustively extracted with $2 \times 400 \mathrm{~mL}$ ethanol and chloroform for 7 days at room temperature with the help of a magnetic stirrer. The collected filtrates were concentrated under vacuum with a rotary evaporator to get the semisolid residue. The ethanol and chloroform extracts were obtained in good yield $(13.5 \%$ and $11.1 \%$ respectively) and preserved in the air tight containers in a refrigerator until used.

Phytochemical screening of ethanol and chloroform extracts of $B$. sacra resin. The $B$. sacra resin extracts were subjected to qualitative screenings to detect the presence of different groups of bioactive phytochemicals such as triterpenoids, steroids, saponins, alkaloids, proteins, free amino acids, phenols and carbohydrates using standard procedures. ${ }^{7}$

Quantification of total phenolic content. The content of total phenolic compounds in the frankincense extracts was assessed colorimetrically employing Folin-Ciocalteu reagent (FCR). ${ }^{8}$ Gallic acid was employed as a reference material to calculate the amount of total phenolics from its standard plot. Briefly, $1 \mathrm{ml}$ of the resin extract ( 8 
$\mathrm{mg} / \mathrm{ml}$ ) was thoroughly mixed with $1.5 \mathrm{ml}$ of the FCR (1:10 dilution with distilled water) followed by the addition of $4.5 \mathrm{ml}$ of $7.5 \% \mathrm{w} / \mathrm{v}$ sodium bicarbonate solution. The solution in the test tube was allowed to stand at an ambient temperature for 30-35 min with occasional shaking for the completion of the reaction. The absorbance of the test and standard solutions was measured at $765 \mathrm{~nm}$ using a colorimeter. The quantity of phenolic compounds in both the extracts have been expressed as gallic acid equivalents (GAE) and were computed with the help of the standard equation for line $(y=m x+c)$ obtained from the gallic acid plot.

Determination of antioxidant activity by DPPH- scavenging assay. The free radical scavenging activity of the frankincense extracts was investigated using DPPH radical scavenging assay method as per the standard procedure. ${ }^{9}$ The test solution was prepared by mixing $2 \mathrm{ml}$ of (40 $\mu \mathrm{g} / \mathrm{ml}$ ) DPPH solution dissolved in ethanol and 1 $\mathrm{mL}$ of both polar and non-polar resin extracts of four different concentrations (2.0 to $8.0 \mathrm{mg} / \mathrm{ml}$ ) were used. The resulting reaction mixture was rapidly mixed and kept in the dark place for 30-35 min. The absorbance of each solution was measured at $517 \mathrm{~nm}$ using colorimeter against the blank. The percentage of DPPH radical scavenging (\%) was determined by the following formula:

$\%$ Free radical scavenging activity

$$
=\frac{\mathrm{Ac}-\mathrm{As}}{\mathrm{Ac}} \times 100
$$

where, $A_{c}=$ Absorbance of control; $A_{s}=$ Absorbance of sample.

Evaluation of in vitro cytotoxicity using brine shrimp lethality (BSL) assay. The cytotoxic activity of both the test extracts was assessed by following brine shrimp lethality assay method. ${ }^{10}$ The artificial sea water ( $30 \mathrm{~g}$ of sodium chloride in $3 \mathrm{~L}$ water) was prepared and added to a water tank to hatch the brine shrimps. Few milligrams of brine shrimp eggs were sprinkled on the surface of water and the tank was half covered to have an equal light and dark region. The aerated water tank was kept in a well-lighted area for hatching. The nauplii hatched within 36-48 hours. Test sample was dissolved in $2 \mathrm{~mL}$ DMSO (Dimethyl sulfoxide) to obtain the stock solution of $10,000 \mu \mathrm{g} / \mathrm{L}$ concentration. The toxicity of samples was tested at various concentrations (10, 100 and $1000 \mu \mathrm{g} / \mathrm{L})$. Ten nauplii were used in each test tube. After 24 hour, the numbers of survivors were counted and the percentage of the mortality $(\% \mathrm{M})$ at each dose was calculated.

Evaluation of antimicrobial activity. The antibacterial activity of the frankincense extracts was determined using the agar disc diffusion protocol. ${ }^{11}$ DMSO was used to prepare the stock solutions $(1000 \mu \mathrm{g} / \mathrm{mL})$ of extracts. Streaking method was adopted to culture the four bacterial strains (Staphylococcus aureus, Bacillus subtilis, Proteus vulgaris and Escherichia coli - ATCC Bacteriology Collection) in the agar plates. Filter paper disc impregnated with the extracts at three different concentrations (250, 500 and $100 \mu \mathrm{g} / \mathrm{disc})$ were added to the plates. Ciprofloxacin antibiotic (30 $\mu \mathrm{g}$ ) disc was used as a standard drug to compare the results. DMSO was used as a negative control. Plates were incubated for 24 hours and then zone of inhibitions were measured in $\mathrm{mm}$.

In silico prediction of bioactivity and cytotoxicity of boswellic acids. Computational studies were also carried out on the four major boswellic acids ( $\beta$-boswellic acid (BA), 11 keto- $\beta$ boswellic acid (KBA), 3-acetyl- $\beta$ - boswellic acid (ABA) and 3-acetyl-11-keto- $\beta$ - boswellic acid (AKBA) to correlate the results of in vitro pharmacological studies. PASS and CLC-pred online software were used to predict the bioactivity and cytotoxicity of boswellic acids. ${ }^{12,13}$

\section{RESULTS AND DISCUSSION}

Phytochemical screening. Qualitative testing of the extracts revealed the presence of major groups of phytochemicals such as tannins, alkaloids, carbohydrates, terpenoids, etc. (Table 1). Protein and amino acids were not detected in the extracts. The presences of these components indicate the biological potential of frankincense. For instance, the presence of phenols could be responsible for its antioxidant and antiinflammatory activities. Triterpenoids are highly lipophilic molecules which are known to exhibit antimicrobial and cytotoxic activities. Tannins precipitate the proteins and can kill the bacteria by destroying its cell membrane. Based on the 
presence of secondary metabolites, the chloroform and ethanol extracts were further evaluated for in vitro biological activities.

Table 1. Preliminary phytochemical analysis of frankincense extracts.

\begin{tabular}{lll}
\hline Chemical class & $\begin{array}{l}\text { Ethanol } \\
\text { extract }\end{array}$ & $\begin{array}{l}\text { Chloroform } \\
\text { extract }\end{array}$ \\
\hline Phenols & + & + \\
Steroids & - & + \\
Saponins & + & - \\
Proteins and amino acids & - & - \\
Alkaloids & + & + \\
Carbohydrates & + & + \\
Terpenoids & + & + \\
\hline
\end{tabular}

(+) means detected; (-) means not detected

Total phenolic content. The quantification of total phenolics was done using the following linear equation obtained from the standard plot of gallic acid $\mathrm{Y}=0.0056 \mathrm{X}-0.0067, \mathrm{R} 2=0.9942$. The total phenolic content expressed in terms of GAE of ethanol and chloroform extracts were found to be $(14.66 \pm 0.12 \mathrm{mg} / \mathrm{g})$ and $(14.79 \pm 0.97 \mathrm{mg} / \mathrm{g})$ of GAE respectively. The phenolic content of both the extracts is almost similar and thus expected to have the similar antioxidant spectrum.

Free radical scavenging activity. The results of the antioxidant activity expressed as inhibition (\%) of DPPH radical are shown Table 2. The scavenging level of the resin extract is indicated by the degree of discoloration of DPPH solution. Frankincense extracts showed a dose dependent increase in scavenging activity. In this study, the ethanol extract showed a slightly higher antioxidant activity (14.26-47.69\%) than the chloroform extract $(13.0-44.75 \%)$. The other species of frankincense namely Boerhavia diffusa and Boswellia serrata have also been reported to exhibit antioxidant activity. ${ }^{14}$

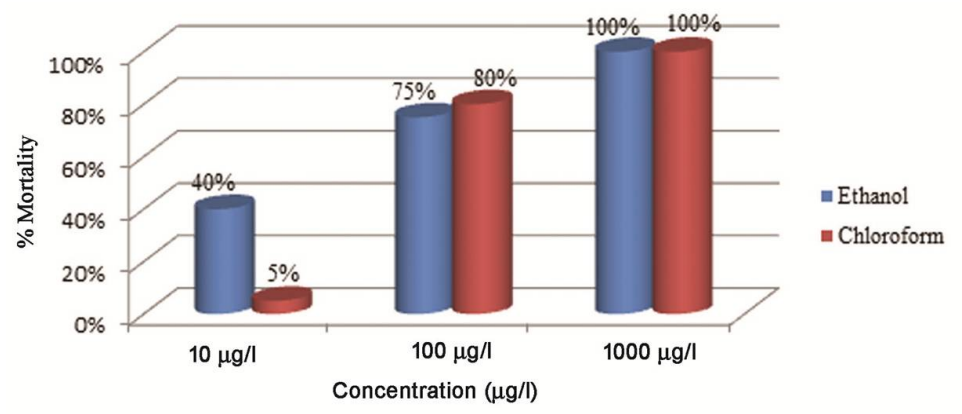

Figure 2. Comparison between \% mortality obtained with ethanol and chloroform extracts of B. sacra after 24 hrs.

Table 2. \% Inhibition of DPPH free radical activity of ethanol and chloroform extracts of $B$. sacra.

\begin{tabular}{llll}
\hline Sl. & Concen- & \multicolumn{2}{c}{ \% inhibition $($ Mean \pm SD) } \\
\cline { 3 - 4 } No. & $\begin{array}{l}\text { tration } \\
(\mathrm{mg} / \mathrm{ml})\end{array}$ & Ethanol extract & Chloroform extract \\
\hline 1 & 2 & $14.26 \pm 0.43$ & $13.00 \pm 0.64$ \\
2 & 4 & $26.85 \pm 0.81$ & $22.37 \pm 3.14$ \\
3 & 6 & $39.30 \pm 0.43$ & $29.79 \pm 2.76$ \\
4 & 8 & $47.69 \pm 0.49$ & $44.75 \pm 1.44$ \\
\hline
\end{tabular}

In vitro cytotoxicity activity by Brine shrimp lethality assay. The results of the cytotoxicity activity are expressed as \% mortality as shown in Figure 2. The highest mortality was observed at $1000 \mu \mathrm{g} / \mathrm{l}$ in both ethanol and chloroform extracts, indicating that frankincense has the best cytotoxic activity at high concentrations. The $\mathrm{LC}_{50}$ for cytotoxicity was calculated using the probit analysis. Ethanol extract had a $\mathrm{LC}_{50}$ of $87.9 \mu \mathrm{g} / \mathrm{l}$ while that of the chloroform extract was found to be $74.51 \mu \mathrm{g} / \mathrm{l}$, which suggested that the non-polar extract has different composition than polar extract. Furthermore, the chloroform extract should have higher content of cytotoxic phytoconstituents than the ethanolic extract.

Antimicrobial activity. The antimicrobial activity of the extracts at different concentrations and ciprofloxacin are shown in Table 3. Ethanolic extract exerted antibacterial activity against $E$. coli (gram negative) only. On the other hand, the chloroform extract showed antibacterial activity against both $E$. coli and B. subtilis but was more effective against the $E$. coli bacteria. Both the extracts inhibited the growth of $E$. coli better than the standard drug ciprofloxacin $(30 \mu \mathrm{g} / \mathrm{disc})$ at the tested concentrations. Surprisingly, neither of the extracts inhibited the growth of $P$. vulgaris and $S$. aureus. Thus, the results of this study confirm that 
frankincense extracts have the ability to inhibit the bacterial growth. Our results are in agreement with the previous study done to evaluate the antimicrobial activity of frankincense (B. serrata) which have also shown high antibacterial activity against gram negative bacteria $($ E. coli $){ }^{14,15}$

Table 3. Antibacterial activity of ethanol and chloroform extracts of $B$. sacra and standard ciprofloxacin.

\begin{tabular}{llll}
\hline Bacteria & \multicolumn{2}{c}{ Zone of Inhibition $(\mathrm{mm})$} \\
\cline { 2 - 4 } & $\begin{array}{l}\text { Ciprofloxacin } \\
(30 \mu \mathrm{g})\end{array}$ & Ethanol extract & Chloroform extract \\
\hline E. coli & 30 & $1000 \mu \mathrm{g} / \mathrm{mL} \rightarrow 37$ & $1000 \mu \mathrm{g} / \mathrm{mL} \rightarrow 36$ \\
& & $500 \mu \mathrm{g} / \mathrm{mL} \rightarrow 34$ & $500 \mu \mathrm{g} / \mathrm{mL} \rightarrow 34$ \\
& $250 \mu \mathrm{g} / \mathrm{mL} \rightarrow 31$ & $250 \mu \mathrm{g} / \mathrm{mL} \rightarrow 30$ \\
P. vulgaris & 33 & - & - \\
S. aureus & 28 & - & - \\
B. subtilis & 24 & - & $1000 \mu \mathrm{g} / \mathrm{mL} \rightarrow 31$ \\
& & & $500 \mu \mathrm{g} / \mathrm{mL} \rightarrow 25$ \\
& & & $250 \mu \mathrm{g} / \mathrm{mL} \rightarrow 21$ \\
\hline
\end{tabular}

Table 4. In silico PASS predicted bioactivities of boswellic acids $(\mathrm{Pa}>0.5)$.

\begin{tabular}{llcccc}
\hline Sl. No. & Bioactivity predicted & \multicolumn{3}{c}{ Pa bioactivity score for } \\
\cline { 3 - 5 } & & BA & KBA & ABA & AKBA \\
\hline 1. & Hepatoprotective & 0.932 & 0.929 & 0.943 & 0.939 \\
2. & Chemopreventive & 0.882 & 0.898 & 0.908 & 0.920 \\
3. & Hypolipemic & 0.910 & 0.888 & 0.925 & 0.906 \\
4. & Anti-inflammatory & 0.897 & 0.905 & 0.899 & 0.894 \\
5. & Antineoplastic & 0.859 & 0.861 & 0.875 & 0.869 \\
6. & Antinociceptive & 0.737 & 0.644 & 0.704 & 0.603 \\
7. & Antifungal & 0.626 & 0.593 & 0.649 & 0.624 \\
\hline
\end{tabular}

Table 5. In silico prediction of cytotoxicity of boswellic acids for tumor and non-tumor cell lines using CLC- Pred.

\begin{tabular}{|c|c|c|c|c|c|}
\hline $\begin{array}{l}\text { Boswellic } \\
\text { acid }\end{array}$ & $\overline{\mathrm{Pa}}$ & $\mathrm{Pi}$ & $\begin{array}{l}\text { (Non-tumor/ Cancer) } \\
\text { Cell line }\end{array}$ & Cell line name & Tissue affected \\
\hline$\overline{\mathrm{BA}}$ & 0.651 & 0.007 & $\begin{array}{l}\text { Non tumor } \\
\text { (MRC5) }\end{array}$ & Embryonic lung fibroblast & Lung \\
\hline \multirow[t]{2}{*}{$\mathrm{KBA}$} & 0.540 & 0.005 & $\begin{array}{l}\text { Cancer cell } \\
\text { (PANC-1) }\end{array}$ & Pancreatic carcinoma & Pancreas \\
\hline & 0.570 & 0.010 & $\begin{array}{l}\text { Non tumor } \\
\text { (MRC5) }\end{array}$ & Embryonic lung fibroblast & Lung \\
\hline $\mathrm{ABA}$ & 0.687 & 0.006 & $\begin{array}{l}\text { Non tumor } \\
\text { (MRC5) }\end{array}$ & Embryonic lung fibroblast & Lung \\
\hline \multirow[t]{2}{*}{ AKBA } & 0.621 & 0.008 & $\begin{array}{l}\text { Non tumor } \\
\text { (MRC5) }\end{array}$ & Embryonic lung fibroblast & Lung \\
\hline & 0.526 & 0.020 & $\begin{array}{l}\text { Non tumor } \\
\text { (WI-38VA13) }\end{array}$ & Embryonic lung fibroblast & Lung \\
\hline
\end{tabular}

In silico and cytotoxicity studies of boswellic acids. The bioactivity score of four naturally occurring boswellic acids predicted by PASS is presented in the Table 4. The probability of the compound to exhibit bioactivity is predicted with the help of $\mathrm{Pa}$ value. A $\mathrm{Pa}$ value of more than 0.5 indicates $50 \%$ probability of the compound to be active. Based on the $\mathrm{Pa}$ values, all the four boswellic acid analogs are predicted to possess potent hepatoprotective (0.929-0.943), chemopreventive (0.882-0.920), hypolipemic (0.888$0.910)$ and anti-inflammatory activities (0.8940.905). Moderate antifungal and antinociceptive activities are also predicted for boswellic acids. The chemopreventive potential of the boswellic acids were found to be the highest for AKBA followed by $\mathrm{ABA}, \mathrm{KBA}$ and then $\mathrm{BA}$. It could be inferred that the presence of acetyl group at $3^{\text {rd }}$ position as in $\mathrm{AKBA}$ and $\mathrm{ABA}$ augments the chemopreventive activity. BA is predicted to have lowest $\mathrm{Pa}$ value of 0.882 for chemopreventive activity, which could be due to the absence of both acetyl group and keto group in its structure. Interestingly BA, devoid of acetyl and keto groups, is predicted to be the most potent compound with antinociceptive activity. On the other hand, both KBA and ABA were predicted to be the most potent hepatoprotective and antiinflammatory compounds. 
Furthermore, to support and correlate the results of in vitro cytotoxicity test, the CLC-pred tool was used to predict the chemopreventive activity of boswellic acids against tumor and nontumor cell lines. All the four boswellic acids are predicted to be active against non-tumor embryonic lung fibroblast (MRC5), while only KBA is expected to exert antineoplastic activity against pancreatic carcinoma cell lines (PANC-1). The Pa values against MRC5 cell lines were found to be in the range of 0.570-0.687 (Table 5) and the activity was found in the following order, $\mathrm{ABA}>\mathrm{AKBA}>$ $\mathrm{BA}>\mathrm{KBA}$.

\section{CONCLUSIONS}

Phytochemical analysis of the ethanol and chloroform extracts of the $B$. sacra revealed the presence of phenolic compounds and alkaloids. Saponins were detected in ethanol extract only while steroids were present in the chloroform extract. A satisfactory in vitro free radical scavenging activity was exhibited by both the extracts but the ethanol extract showed slightly better activity. Cytotoxic activity by the brine shrimp lethality assay revealed a very good activity for both extracts and was found to be dose dependent. Frankincense extracts showed excellent antibacterial against $E$. coli strain but failed to inhibit the growth of $S$. aureus and $P$. vulgaris. The ethanol extract was active against gram negative bacteria while the chloroform extract was effective against both gram positive and gram negative bacteria with better activity against later.

The study demonstrated that the frankincense extracts have potentials for being a leading product in drug and cosmetic industries.

\section{ACKNOWLEDGMENTS}

The authors thank the Dean of College of Pharmacy, National University of Science and Technology for providing the necessary research facilities and infrastructure. Authors also feel indebted to Ms. Amal A. Al Lawati for her guidance in performing the antibacterial studies.

\section{CONFLICTS OF INTEREST STATEMENT}

The authors declare no conflict of interest.

\section{REFERENCES}

1. Al-Harrasi, A., Rehman, N.U., Khan, A.L., Al Broumi, M., Al-Amri, I., Hussain, J. Hussain, H. and Csuk, R. 2018. Chemical, molecular and structural studies of Boswellia species: $\beta$-boswellic aldehyde and 3-epi11 $\beta$-dihydroxy ba as precursors in biosynthesis of boswellic acids. PLoS ONE. 13, e0198666

2. Al-Saidi, S., Rameshkumar, K.B., Hisham, A., Sivakumar, N. and Al-Kindy, S. 2012. Composition and antibacterial activity of the essential oils of four commercial grades of Omani luban, the oleo-gum resin of Boswellia sacra. Chem. Biodivers. 9, 615-624.

3. Iram, F., Khan, S.A. and Husain, A. 2017. Phytochemistry and potential therapeutic actions of boswellic acids: a minireview. Asian Pac. J. Trop. Biomed. 7, 513-523.

4. Khan, A.J. 2012. Medicinal properties of frankincense. Int. J. Nutr. Pharmacol. Neurol. Dis. 2, DOI: 10.4103/22310738.95925.

5. Ahmad, S., Khan, S.A., Kindelin, A., Mohseni, T., Bhatia, K., Hoda, M.N., Ducruet and A.F. 2019. Acetyl-11-keto $\beta$ boswellic acid (AKBA) attenuates oxidative stress inflammation complement activation and cell death in brain endothelial cells following OGD/reperfusion. Neuromol. Med. 21, 505-516.

6. Cragg, G.M. and Newman, D.J. 2013. Natural products: a continuing source of novel drug leads. Biochim. Biophys. Acta. 1830, 3670-3695.

7. Al-Brashdi, A.S., Al-Ariymi, H., Al Hashmi, M. and Khan, S.A. 2016. Evaluation of antioxidant potential, total phenolic content and phytochemical screening of aerial parts of a folkloric medicine, Haplophyllum tuberculatum (Forssk) A. Juss. J. Coastal Life Med. 4, 315-319.

8. Al Hakmani, F., Kumar, S. and Khan, S.A. 2013. Estimation of total phenolic content, in-vitro antioxidant and anti-inflammatory activity of flowers of Moringa oleifera. Asian Pac. J. Trop. Biomed. 3, 623-627.

9. Ahmad, A., Husain, A., Mujeeb, M., Khan, S.A., Alhadrami, H.A.A. and Bhandari, A. 2015. Quantification of total phenol, flavonoid content and pharmacognostical evaluation including HPTLC fingerprinting for the standardization of Piper nigrum Linn fruits. Asian Pac. J. Trop. Biomed. 5,101-107.

10. Abdelrahman, M.H., Hussain, R.O., Shaheed, D.S., AbuKhader and M., Khan, S.A. 2019. Gas chromatographymass spectrometry analysis and in vitro biological studies on fixed oil isolated from the waste pits of two varieties of Olea europaea L. Oilseeds \& Fats Crops and Lipids (OCL). 26, 28.

11. Balouiri, M., Sadiki, M. and Ibnsouda, S.K. 2016. Methods for in vitro evaluating antimicrobial activity: a review. $J$. Pharm. Anal. 6, 71-79.

12. Lagunin, A.A., Dubovskaja, V.I., Rudik, A.V., Pogodin, P.V., Druzhilovskiy, D.S. and Gloriozova, T.A. 2018. CLCPred: A freely available web-service for in silico prediction of human cell line cytotoxicity for drug-like compounds. PLOS ONE. 13, e0191838.

13. Ahmad, A., Husain, A., Khan, S.A., Mujeeb, M. and Bhandari, A. 2015. Design, synthesis, molecular properties and antimicrobial activities of some novel $2(3 \mathrm{H})$ pyrrolone derivatives. J. Saudi Chem. Soc. 19, 340-346.

14. Singh, H.P., Yadav, I.K., Dinesh Chandra, D. and Jain, D.A. 2012. In vitro antioxidant and free radical scavenging activity of different extracts of Boerhavia diffusa and Boswellia serrata. IJPSR. 3, 503-511.

15. Ismail, S.M., Aluru, S., Sambasivarao, K.R.S. and Matcha, B. 2014. Antimicrobial activity of frankincense of Boswellia serrata. Int. J. Curr. Microbiol. Appl. Sci. 3, 1095-1101. 